\title{
Assessing dynamic capabilities: Mintzberg's schools of thought
}

\author{
F. Arndt* \\ Udo Staber, University of Canterbury \\ ffarndt@gmail.com
}

Received June 2010

\begin{abstract}
A growing body of research in strategic management has focused on dynamic capabilities as a central source of firms' competitive advantage. The theoretical roots of dynamic capabilities can be found in many of the schools of thought identified by Mintzberg, Ahlstrand and Lampel (1998). In this paper, we identify three aspects of dynamic capabilities that, we believe, require more detailed attention: Process, cognitive and decision-based micro-foundations, and human agency. We explore each of these areas from an evolutionary perspective to emphasize the fact that dynamic capability is essentially an evolutionary construct. By highlighting the evolutionary implications of these areas, we add important detail to the way "evolution" has been used in this field of research.
\end{abstract}

*To whom all correspondence should be addressed.

\section{Introduction}

The field of strategic management is concerned with the fundamental question of how firms develop and sustain competitive advantage. Over the years, investigators have increasingly looked to dynamic capabilities "to integrate, build, and reconfigure internal and external competencies" (Teece, Pisano \& Shuen, 1997: 516) as an important source of competitive advantage. While there has been much progress in this field of research, there are several aspects of dynamic capabilities that, we believe, would benefit from more detailed analysis. First, the discussion of dynamic capabilities has typically been couched at a highly aggregated level. Not attending to the micro-foundations of capability development makes it difficult to appreciate the cognitive and decision-based aspects of strategy formation in a changing environment. Second, research has focused on the content properties of dynamic capabilities, such as the characteristics of a particular routine, while downplaying the process aspects, such as how rules can be changed to fit new circumstances. This is curious because the construct of dynamic capability was introduced originally to address the dynamic aspects of strategic management. Ignoring process makes it difficult to understand how dynamic capabilities evolve endogenously. Third, previous research has shown insufficient concern for the role of management in actively shaping the process by which dynamic capabilities develop. On the whole, these shortcomings have led to a rather restricted view of dynamic capabilities.

Our objective in this paper is to advance the understanding of dynamic capabilities by addressing the above shortcomings from an evolutionary perspective. We suggest that an approach that uses evolutionary concepts (e.g., adaptation, adaptive complexity, differential fitness) and specifies the evolutionary mechanisms of adaptability development (e.g., learning, imitation, selection) can generate new insights and refine theorizing about dynamic capabilities. We note that the use of "evolution" in the dynamic capability literature has generally been more metaphorical than analytically rigorous, perhaps because of difficulties in measuring variables and mechanisms (Danneels, 2008), which has caused some researchers to resort to simulation studies (Gavetti, 2005). Although much progress has been made in recent studies, overall this literature has yet to produce generalizable propositions concerning the rate, direction, and performance outcomes of capability development.

We begin this paper by defining dynamic capabilities and by briefly reviewing the main arguments in the perspectives identified by Mintzberg et al. (1998). Their contribution was to identify and conceptualize a range of schools of thought that speak to the sources and challenges of managing competitive advantage. Most of these schools have sensitized researchers in strategic management to the concept of dynamic capabilities, in terms of concepts that can be traced back to the behavioural theory of the firm, transaction cost economics, and economic-evolutionary theory (Augier \& Teece, 2009). These schools of thought highlight various aspects of dynamic capabilities which, we suggest, can be usefully interpreted from a general evolutionary perspectives (Heil, Maxwell \& Whittaker, 2003). Given limited space in this paper, we do not develop a full-blown account of evolutionary theory and its application to research on dynamic capabilities. We do, however, identify those areas where evolutionary concepts can yield new insights. Figure 1 shows the areas we draw attention to and suggests that the schools of thought identified by Mintzberg et al. (1998) are implicated in each of these areas. 


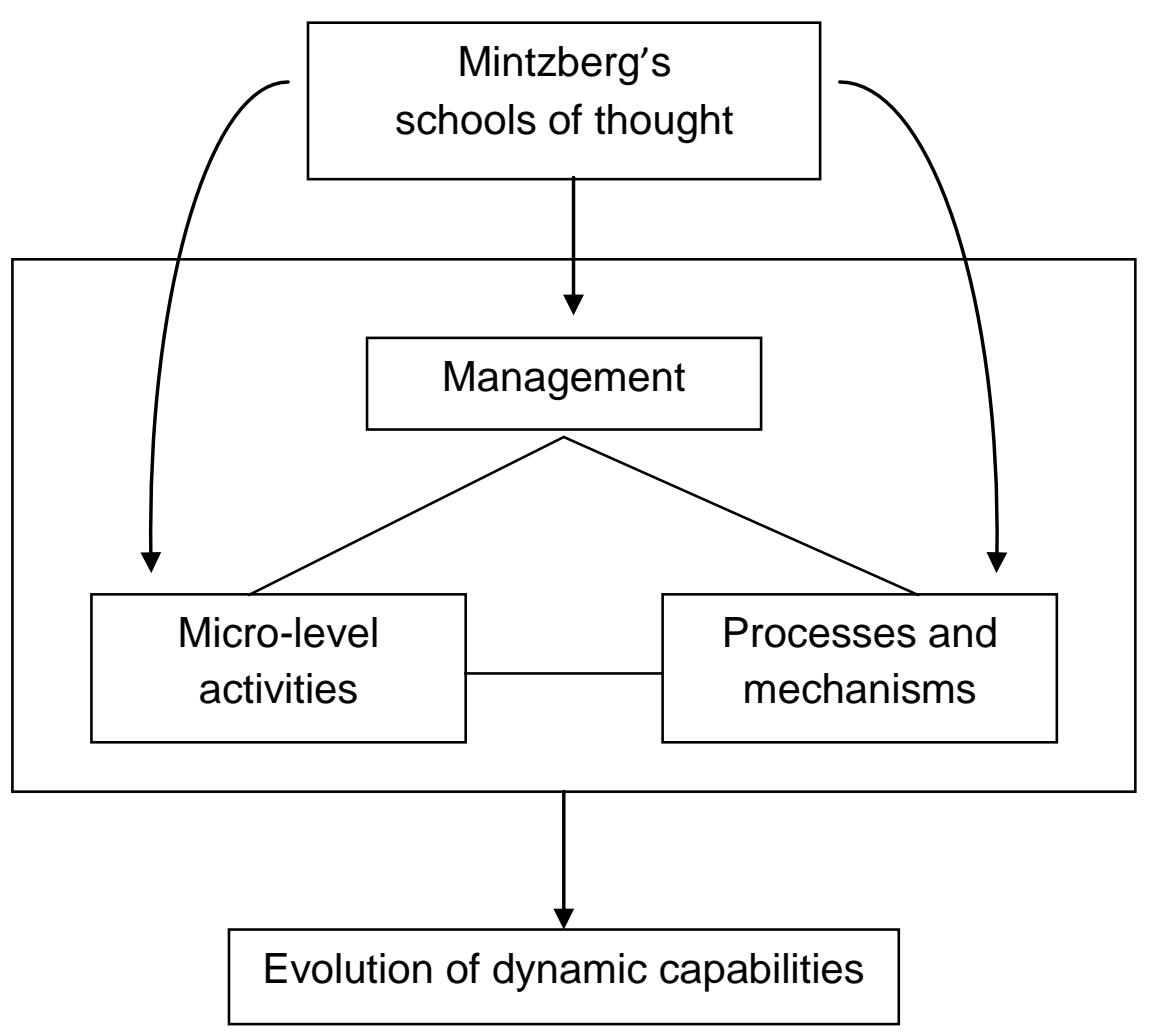

Figure 1: Elements of the evolution of dynamic capabilities

\section{What are dynamic capabilities?}

The discussion of dynamic capabilities has emerged out of the resource-based view which characterizes the firm as a bundle of resources (Penrose, 1959). Dynamic capabilities refer to the firm's ability to alter its resource base by creating, integrating, and reconfiguring its internal and external competencies to cope with the demands of a volatile environment (Peteraf \& Barney, 2003; Teece, 2007). Embedded in this definition is the view that dynamic capabilities have three components: Sensing, seizing, and implementing, interpreted as follows:

- The ability to sense environmental demands, by monitoring emerging opportunities in new markets and technologies. Ambrosini and Bowman (2009) consider managers' sensing ability the macro-foundation of dynamic capabilities, whereas Teece (2007) suggests that this ability relates more to the micro-level entrepreneurial aspects of management intervention.

- The ability to seize opportunities and threats, by analyzing new information through a variety of channels. Firms may use interpersonal relations, social networks, or interest associations to learn about opportunities and threats, and to develop new competencies for dealing with them.

- The ability of managers to implement the organizational and inter-organizational changes that may be necessary as the firm responds to new opportunities, while neutralizing the threats. Effective implementation depends on the understanding and support of all relevant actors in the organization who need to agree to transformations in routines and rules.

Below, we summarize the arguments from several theoretical perspectives that have been used to understand the nature and development of dynamic capabilities.

\section{Perspectives on dynamic capabilities}

To describe the strategy formation process, Mintzberg et al. (1998) identified ten schools of thought, including three prescriptive and six descriptive schools. Of these, we select four schools which provide most insight into various aspects of dynamic capabilities, including those that emphasize their evolutionary nature. Before doing so, we briefly explain the function of dynamic capabilities in the conventional strategic business process, as depicted in Figure 2.

Dynamic capabilities are part of the resource base of a firm. For analytical reasons, we extract them from the resource base and discuss their role within strategy formation. The business process starts with the identification of resource needs through the evaluation of decision drivers. In a rational strategy model, these drivers are the business environment as well as the firm's vision and mission. We call the fit between the current resource base and an aspired resource set, based on the firm's strategic goals, the resource gap. Dynamic capabilities enable the firm to close the resource gap in line with the requirements envisioned by management. Managers use dynamic capabilities to reconfigure the firm's resource base in response to environmental demands. 


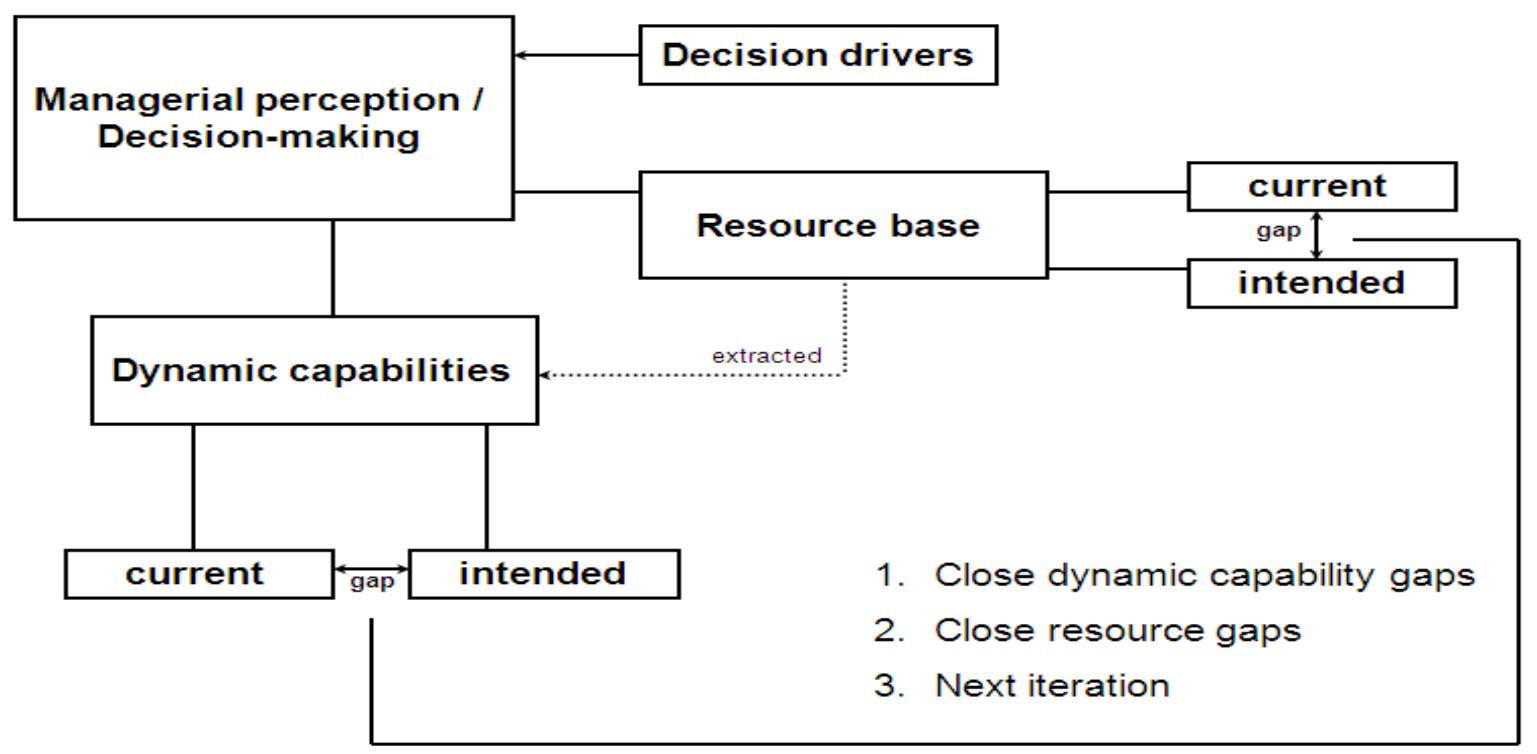

\section{Figure 2: Strategy formation and the role of dynamic capabilities}

\section{Prescriptive schools}

The prescriptive schools identified by Mintzberg et al. (1998) characterize strategy formation as "one big creative act" of a top-manager who strategizes to find the best fit between internal organizational capabilities and external opportunities and threats. Strategic choices, which may derive from formal analyses such as the SWOT approach, concern the need for and the availability of future resources. Choices for resource allocation are implemented through planning and budgeting processes. In prescriptive models, competitive advantage is gained through "distinct competencies" which originate in the firm's initial resource configuration, evolve in a path-dependent fashion, and are fully accounted for in the decision preparation scenarios.

Given several restrictive assumptions, prescriptive schools can serve as no more than a starting point to understand strategy formation. First, prescriptive schools describe strategy formation of firms operating in essentially stable environments. Second, managers are assumed to be rational and have perfect information when choosing from a small set of full-blown strategies. And third, competencies are treated as synonymous with dynamic capabilities, rather than as distinct components of dynamic capabilities, on the assumption that all competencies evolve along the same path. Given these restrictive assumptions, it is difficult to analyze the dynamic and configurational aspects of dynamic capabilities. Four of the descriptive schools identified by Mintzberg et al. (1998) have moved beyond these assumptions, by suggesting how strategy models can be adapted to firms' unique circumstances. We discuss these schools separately to show their unique contribution to our understanding of the process of "closing the gap" in the strategy formation process (Figure 2).

\section{Entrepreneurial school}

Many researchers think of entrepreneurial capabilities as the heart of management. Entrepreneurship is about perceiving business opportunities through creatively combining disparate elements, while breaking old habits and routines, without employing the excessive bureaucracy of a formal strategic analysis. The picture of the entrepreneurial manager is that of a central, single decision-maker who takes a proactive approach, has a clear vision and deep knowledge, is charismatic, exercises good judgment, and is able to adapt ideas swiftly to new conditions.

This school has made a major contribution to the study of all three components of dynamic capabilities, supported by considerable research evidence. Brinkmann (2006), for example, finds that successful high-technology start-ups match the unique requirements of each development stage with a particular set of management skills. Nevertheless, our understanding of the entrepreneurial aspects of dynamic capabilities is still in its infancy. In particular, research has focused more on the process of seizing opportunities and implementing strategic choices than the entrepreneurial sensing of opportunities and the generation of new ideas.

\section{Learning school}

The learning school is a valuable and much used approach to the study of dynamic capabilities. For example, investigators have used learning concepts and models to explain how incremental improvements can be accomplished to integrate emergent strategies as part of an overall business strategy. Researchers have also drawn on learning theories to show how experience can be leveraged 
to create routines with which different kinds of capabilities can be strengthened. In particular, learning-theoretic arguments are used to explain the integration of knowledge held by front-line managers and middle-managers, by identifying mechanisms that support the articulation, codification, sharing, and internalization of knowledge throughout an organization (Pretorius \& Steyn, 2005).

Some investigators go as far as to characterize dynamic capabilities as learning capabilities (Zollo \& Winter, 2002), suggesting that firms need to be able to "learn how to learn" as a way to improve organizational adaptive complexity. However, learning capabilities are costly to build and, therefore, will not produce an adaptive advantage in any environment. Developing a broad range of learning capabilities may have no payoff in an environment that rarely changes. When environments change abruptly and radically, learning capabilities are required that contradict the learning school's focus on incremental improvement. There may also be a conflict between the firm's overall, long-term strategy and the partial, emergent strategies employed by middle-managers (Burgelman, 1991), reflecting conditions under which variation within the firm does not produce adaptive advantage.

\section{Power school}

The power school characterizes strategy formation as essentially a decision-making process, driven by interpretation and negotiation, and leading to dynamic capabilities as a set of components that are "... envisioned and deemed appropriate by its principal decision-maker(s)" (Zahra, Sapienza \& Davidsson, 2006: 918). This school assumes that strategy is developed in a process of negotiation in which the strongest decision-makers can successfully enforce their strategy. From this perspective, the firm's (shifting) resource configuration is thus a reflection of the distribution of power in the organization, and not necessarily a reflection of the requirements of evolving environments.

By suggesting that the negotiation process is grounded in the firm's previous decisions, which themselves reflect the historical distribution of power, the power school points to the path dependency inherent in capability development. One reason for path dependency is that decision-making often reflects managers' personal interests or their particular reading of environmental demands, causing resistance to alternative interpretations and actions. In evolutionary terms, managers' selection of dynamic capability components may not be consistent with external selection criteria, potentially leading to sub-optimal organizational performance. On the other hand, such inconsistencies are also a source of variations, some of which may have adaptive value in a changing environment.

\section{Environmental school}

The population ecology perspective is at the center of the environmental school. The unit of analysis is the population of firms (rather than individual firms), and the population is seen as evolving along the terms on which environmental resources are available. Change in the population occurs through (external) selection rather than (internal) adaptation of individual firms, largely due to firms' inability to change quickly enough to keep pace with environmental change. Increases in structural inertia (e.g., fixed routines, vested interests) in a population are the result of evolutionary processes that selectively favor inertia.

Dynamic capabilities may be seen as a way for firms to overcome pressures towards inertia (Schreyögg \& KlieschEberl, 2007), but whether such efforts lead to success is a question that is ultimately determined at the level of environmental selection. Firm survival often depends on small differences in the co-existence of several organizational features, including the components of dynamic capabilities, and the co-occurrence of several events in the environment. Rapid changes in selection environments can alter the terms on which resources are available, thus affecting the speed with which firms can adapt to new circumstances.

In summary, the descriptive schools illustrate the range of approaches with which researchers have examined various aspects of dynamic capabilities. By highlighting issues related to variation, path dependency, adaptation, and environment, they contain the rudiments of an evolutionary perspective. In the discussion below, we use basic ideas from evolutionary theory to obtain a better understanding of the essence of dynamic capabilities, namely the transient nature of capability configurations.

\section{The evolutionary nature of dynamic capabilities}

Dynamic capabilities are an evolution-theoretic construct. They are directly implicated in the (development of the) firm's adaptive complexity. If we think of the firm as an evolved structure, we can expect increases in complexity to occur through the hierarchical bundling of units, including distinct capabilities related to sensing, seizing, and transformational activities, and selected through the conscious decisions of individuals (Lovas \& Ghoshal, 2000). The logic of complexity (Simon, 1962) is such that in every generation those capabilities with the most advantageous variations will be those that are selected. The evolving structure of capabilities must, therefore, be functional every step of the way, and each intermediate step must be superior to its predecessor, given certain assumptions about the stability of environmental selection criteria. While the maturity process of a given capability takes shape incrementally, dynamic capabilities also face the challenge of supporting organizational adaptation during times of radical change. In highly volatile environments, or in environments where change is rare but dramatic, the firm's exploration activities require constant adjustment in the mix of capability components. Managers' responsibility is to perceive environmental volatility correctly (Stuart \& Podolny, 1996), in order to find the right mix of capabilities, and to implement this mix in a way that supports continuous reconfiguration, if necessary (Newey \& Zahra, 2009).

Dynamic capabilities evolve in a path-dependent fashion. That is, what is already known, or what has already been done, shapes what can be learned and done in the future because of the effect that new information has on other 
elements of the firm and the need for some degree of structural consistency. Any equilibrium achieved depends partly on the process of reaching this equilibrium. The outcome of a path-dependent process may not converge to a unique equilibrium but may lead to one of several possible equilibria, thus maintaining or introducing new variation that is the raw material for the further development of capabilities. When chasing a moving target, such as a competing firm, it may not be desirable to find the optimal solution for any given point in time due to the evolving complexity of the system. Sensing and understanding uncertainty ex ante leads to a greater appreciation of purposive variation, although the adaptive value of a firm's resource configuration can only be calculated ex post. Below, we outline three areas in the literature on dynamic capabilities that would benefit from more analytical rigour: process, micro-foundations, and management action.

\section{Processes}

The processual elements of dynamic capabilities reflect the fact that capabilities are socially constructed, based on decisions concerning the selection and transformation of capabilities. The focus of an evolutionary analysis is on the processes by which the reciprocal relationships between units of selection (such as components of capabilities) and the environment (such as firms or markets) lead to cumulative change in the characteristics of the units over time. There is often a great deal of variation in the set of capabilities one finds in a given firm or population of firms. Much of this variation arises from psychological, sociocultural, and developmental factors that are related, either directly or indirectly, to the ability of individuals and groups in the organization to apply capabilities and to compete successfully for valued resources. Capabilities arise and spread through firms and populations by means of culturally mediated processes, reflecting conformity pressures, social biases, and so forth. Asymmetries between persons and groups influence the selection of particular capabilities and, thus, their evolution within the organization (Taylor \& Helfat, 2009). These processes are evolutionary in the sense that the more successful (components of) capabilities are more likely to be imitated and retained, and then proliferate. The concept of path dependence complements the analysis of process. Path dependence means that the firm's current resources shape their evolution in the future. According to Cyert and March (1963), path dependence may result from individuals' bounded rationality, which limits the amount of knowledge and information a firm can work with and which constrains variation, narrows selection, and, therefore, constrains evolutionary possibilities. Madhok (1997) has summarized these arguments with respect to how new knowledge is related to the existing stock of knowledge, and how these relationships create new resources that are specific to the firm and thus a source of competitive advantage. The same rationality constraints apply to the development of dynamic capabilities. Studying capability evolution in light of these constraints helps clarify the role of dynamic capabilities in the firm's evolving adaptive complexity. We note that while dynamic capabilities may evolve in a path-dependent fashion, they may also carry the potential to break paths and to help the firm find radically new solutions. Research in strategic management has generally ignored these questions of path dependence, similar to the literature on organizational absorptive capacity (Easterby-Smith et al., 2008).

\section{Micro-foundations}

There is no agreement in the strategy literature on the question whether the main sources of competitive advantage are located at the macro or the micro level. While most schools identified by Mintzberg et al. (1998) propose arguments at a more aggregate level, others suggest that a firm's competitive advantage is built at the micro-level of problem-solving and decision-making (Gavetti, 2005; Teece, 2007). The main concern at the micro-level is not the actor's structural position in the firm, but the "actual life" of strategy formation, including how knowledge is managed, social relationships are forged, and incentive systems are implemented (Gomes \& Joglekar, 2008).

Research on dynamic capabilities would gain from paying more attention to cognitive factors in the evolution of capabilities, similar to the conceptualization of organizations and environments as cognitions in the minds of actors. For example, arguments from the power school in strategic management could be combined with findings from research on individuals' perceptions of social network actors and relationships in knowledge transfer (Argote, McEvily \& Reagans, 2003). The cognitive approach reminds us that different individuals often perceive different aspects when looking at the same set of relationships. Studies have shown that actors" understanding of the "true" network is influenced by how stable and schematic their perceptions have become as a result of recurrent interaction experience and the network position of salient actors (Freeman, Romney \& Freeman, 1987). When central actors persist in perceiving and selecting certain patterns, they tend to ignore information with potentially greater adaptive value. The social construction of dynamic capabilities is, therefore, constrained by the perceptual framings that signal opportunities and threats, as when CEOs of poorly performing firms seek advice from their network of close friends rather than from individuals at the periphery of their network (McDonald \& Westphal, 2003; Durbach \& Parker, 2009). The study of how discrepancies between potential and realized competitive advantage are created and resolved is a fruitful but underexplored area in the literature on dynamic capabilities.

We also note that there is no precise conceptualization in this literature of "resources" (Priem \& Butler, 2001). It is not clear whether a given capability is to be seen as a resource or whether it is to be regarded as a means to gain access to resources. This makes it difficult to determine if it is the configuration of a firm's capabilities in coherent bundles that produces an adaptive advantage, as suggested by transaction cost economists, or whether it is variation in bundles that is the source of adaptive complexity, as argued by evolutionary theorists.

Related to the question of coherence is the issue of the mechanisms by which particular capabilities lead to particular outcomes. The study of mechanisms would add substance to the idea that, for example, firms with an 
"innovative capability" are more successful or have a more integrated culture, useful for reconfiguring capabilities. The study of mechanisms would also offer a greater sense of causality and temporality in the development and performance consequences of dynamic capabilities. The investigation of mechanisms connecting intentions and outcomes is hampered by the difficulty of distinguishing between substantive and dynamic features of capabilities. Explorative research concerning the micro-foundations of dynamic capabilities would surely help to remedy this shortcoming. Teece's (2007) distinction between the three components of dynamic capabilities offers a useful point of departure for such research, to help understand the substantive distinctions between components as well as the orchestration of these components. Complexity theory, which is dedicated to the study of micro-level relationships, could also offer important insights in this regard (McKelvey, 1997), adding to the full range of theoretical perspectives through which a more comprehensive understanding of dynamic capabilities can be obtained.

\section{The role of management}

The schools of thought identified by Mintzberg et al. (1998) characterize the role of management rather differently, for example by describing management as proactive, reactive, or controlling. We suggest that research on dynamic capabilities would benefit from specifying the agentic features of management. Managers are actively involved in creating new capabilities and abandoning out-dated capabilities, given their perception of environmental demands. However, managerial intentions do not always have the intended outcomes, because actors are restricted by limited resources, path dependence, bounded rationality, perceptual errors, organizational politics, and so forth. When radically new capabilities need to be developed, managers often fall into competency traps. It is not clear what kinds of capabilities are required to prevent this from happening. This is an area where further research is sorely needed.

Despite being constrained by cognitive and organizational limitations, there is much that managers can do to develop and adjust capabilities. For example, an explicit orientation to proactivity may enable managers to improve organizational adaptability by increasing variation in competencies, as discussed in the literature on diversity management. The entrepreneurship literature has identified conditions under which managers can develop competencies to influence the creation of new markets. Market orientation could be identified as an attribute driving superior firm performance (Morgan, Vorhies \& Mason, 2009). Reflexive management is much more than what Moliterno \& Wiersma (2007) mean when they argue that managers act as a "trigger" of dynamic capabilities by stimulating discrepancies between ambitions and achievements in firm performance. Reflexivity means that managers, as "knowledgeable agents" (Giddens, 1984), can actively monitor and influence evolutionary processes, although they normally cannot fully control them. By affecting the structure of variation and selection, they can "guide evolution" (Lovas \& Ghoshal, 2000), rather than be governed by it.
In summary, dynamic capabilities are often conceptualized in a way that makes it difficult to distinguish between their presence and a particular performance outcome (Zahra et al., 2006). This is evident in the absence of convincing empirical indicators of capabilities, which need to be defined independently of the outcomes of capabilities (Helfat et al., 2007). We think that process oriented and micro-level research would add important insights to our understanding of dynamic capabilities, by highlighting those evolutionary features that indicate constraints as well as opportunities for change.

\section{Implications for research and practice}

The tendency to study dynamic capabilities as a unitary construct has non-trivial consequences for theory development and managerial practice. With respect to improving theoretical understanding, we suggest that empirical research would benefit from a more systematic analysis of the way human agency is implicated in the evolution of dynamic capabilities. The set of people who make decisions concerning dynamic capabilities does not normally constitute a coherent and well-integrated entity. First, the knowledge that individuals possess is typically heterogeneous; it originates from different sources and leads to different responses. From an evolutionary perspective, variation in the firm's knowledge base can be a source of competitive advantage in volatile environments, but this variation must be managed to produce the intended outcomes. Second, the application of knowledge is often "causally ambiguous," constraining knowledge transfer and limiting the imitability of capabilities. For example, the strategy map is a popular instrument for communicating strategy. While it provides a convenient short-cut to the development of a full-blown strategy, it leaves open a variety of interpretations, potentially creating contradictions in the operational strategy process. This may lead to a situation where relationships at the micro-level generate outcomes that are not consistent with those at the aggregate level.

Viewing dynamic capabilities as a composite entity, and understanding how this entity is incorporated in the firm's knowledge bases, has direct implications for improving management practice. Managers have to ensure the complementarity of different sources of knowledge so that they can allocate resources effectively. In particular, we need to better understand the conditions under which managers should replicate rather than modify existing rules and routines. The everyday reality of management is the outcome of decisions shaped by past social and environmental selection and by managers' attempts to reflexively design the selection process.

In conclusion, we suggest that progress in understanding dynamic capabilities will come from systematic research on the evolutionary processes through which the various components of dynamic capabilities co-evolve. It will also come from a more explicit consideration of managers as agents and reflexive decision-makers who are limited by cognitive and organizational restrictions that they can at least partly repair (Heath, Larrick \& Klayman, 1998). Managers can be effective if they understand the full range 
of available strategic choices, appreciate the variable competencies of organization members, and make strategic decisions based on this knowledge, while recognizing that all competitive advantages are inherently transient.

\section{References}

Ambrosini, V. \& Bowman, C. 2009. 'What are dynamic capabilities and are they a useful construct in strategic management?', International Journal of Management Reviews, 11(1): 29-49.

Argote, L., McEvily, B. \& Reagans, R. 2003. 'Managing knowledge in organizations: An integrative framework and review of emerging themes', Management Science, 49(4): 571-582.

Augier, M. \& Teece, D. 2009. 'Dynamic capabilities and the role of managers in business strategy and economic performance', Organization Science, 20(2): 410-421.

Brinkman, J. 2006. Competence of top management teams and the success of new technology-based firms. A theoretical and empirical analysis concerning competencies of entrepreneurial teams and the development of their ventures. Wiesbaden: Gabler.

Burgelman, R.A. 1991. 'Intraorganizational ecology of strategy making and organizational adaptation: Theory and field research', Organization Science, 2(3): 239-62.

Cyert, R. M. \& March, J. 1963. A behavioral theory of the firm. New Jersey: Prentice Hall.

Danneels, E. 2008. 'Organizational antecedents of secondorder competences', Strategic Management Journal, 29: 519-543.

Durbach, I. N. \& Parker, H. 2009. 'An analysis of corporate board networks in South Africa', South African Journal of Business Management, 40(2): 15-26.

Easterby-Smith, M., Graça, M., Antonacopoulou, E. \& Ferdinand, J. 2008. 'Absorptive capacity: A process perspective', Management Learning, 39(5): 483-501.

Freeman, I., Romney, A. \& Freeman, S. 1987. 'Cognitive structure and informant accuracy', American Anthropologist, 89: 310-325.

Gavetti, G. 2005. 'Cognition and hierarchy: Rethinking the microfoundations of capabilities' development', Organization Science, 16(6): 599-617.

Giddens, A. 1984. The constitution of society. Cambridge: Polity Press.

Gomes, P.J. \& Joglekar, N.R. 2008. 'Linking modularity with problem solving and modulation efforts', Managerial and Decision Economics, 29: 443-457.

Heath, C., Larrick, R. \& Klayman, J. 1998. 'Cognitive repairs: How organizational practices can compensate for individual shortcomings', Research in Organizational Behavior, 20: 1-37.

Heil, D., Maxwell, T. \& Whittaker, L. 2003. 'Towards the very nature of strategy', South African Journal of Business Management, 34(1): 1-11.

Helfat, C.E., Finkelstein, S., Mitchell, W., Peteraf, M., Singh, H., Teece, D. \& Winter, S. 2007. Dynamic capabilities: Understanding strategic change in organizations. London: Blackwell.

Lovas, B. \& Ghoshal, S. 2000. 'Strategy as guided evolution', Strategic Management Journal, 21: 875-896.

Madhok, A. 1997. 'Cost, value and foreign market entry mode: The transaction and the firm', Strategic Management Journal, 18(1): 875-896.

McDonald, M. \& Westphal, J. 2003. 'Getting by with the advice of their friends', Administrative Science Quarterly, 48: $1-32$.

McKelvey, B. 1997. 'Quasi-natural organization science', Organization Science, 8: 352-380.

Mintzberg, H., Ahlstrand, B. \& Lampel, J. 1998. Strategy safari: A guided tour through the wilds of strategic management. New York: Prentice-Hall.

Moliterno, T. \& Wiersma, M. 2007. 'Firm performance, rent appropriation, and the strategic resource divestment capability', Strategic Management Journal, 28: 1065-1087.

Morgan, N.A., Vorhies, D.W. \& Mason, C.H. 2009. 'Market orientation, marketing capabilities, and firm performance', Strategic Management Journal, 30(8): 909-920.

Newey, L. \& Zahra, S. 2009. 'The evolving firm: How dynamic and operating capabilities interact to enable entrepreneurship', British Journal of Management, 20: S81S100.

Penrose, E.T. 1959. The theory of growth of the firm .New York: Wiley.

Peteraf, M. \& Barney J. 2003. 'Unraveling the resource based tangle', Managerial and Decision Economics, 24: 309-323.

Pretorius, C. J. \& Steyn, H. 2005. 'Knowledge management in project environments', South African Journal of Business Management, 36(3): 41-50.

Priem, R.L. \& Butler, J.E. 2001. 'Is the resource-based "view" a useful perspective for strategic management research?', Academy of Management Review, 26(1): 22-40.

Schreyögg, G. \& Kliesch-Eberl, M. 2007. 'How dynamic can organizational capabilities be? Towards a dual-process model of capability dynamization', Strategic Management Journal, 28: 913-933. 
Simon, H. 1962. 'Architecture of complexity'. In Proceedings of the American Philosophical Society, 106(6):467-482.

Stuart, T. \& Podolny, J. 1996. 'Local search and the evolution of technological capabilities', Strategic Management Journal, 17: 21-38.

Taylor, A. \& Helfat, C. 2009. 'Organizational linkages for surviving technological change: Complementary assets, middle management, and ambidexterity', Organization Science, 20(4): 718-773.

Teece, D. 2007. 'Explicating dynamic capabilities: The nature and microfoundations of (sustainable) enterprise performance', Strategic Management Journal, 28: 13191350 .

Teece, D., Pisano, G. \& Shuen, A. 1997. 'Dynamic capabilities and strategic management', Strategic Management Journal, 18: 509-533.

Zahra, S.A. \& George, G. 2002. 'Absorptive capacity: A review, reconceptualization, and extension', Academy of Management Review, 27(2): 185-203.

Zahra, S. A., Sapienza, H. J. \& Davidsson, P. 2006. 'Entrepreneurship and dynamic capabilities: A review, model, and research agenda', Journal of Management Studies, 43(4): 917-955.

Zollo, M. \& Winter, S. G. 2002. 'Deliberate learning and the evolution of dynamic capabilities', Organization Science, 13: 339-351. 